\title{
DISCOVERIES THROUGH CHALLENGES: COLLECTIVE AUTOETHNOGRAPHIC STUDY OF TEACHER EDUCATORS IN THE COVID'19 SITUATION
}

\author{
Eglè Pranckūnienè, Rūta Girdzijauskienè, Remigijus Bubnys, \\ Liudmila Rupšienè \\ Klaipèda University, Lithuania
}

\begin{abstract}
After the World Health Organization announced the COVID-19 pandemic in March 2020, education systems were forced to move instruction to the virtual world. It drastically changed the interplay between teachers and learners, educational content, and the learning environment. When scrutinising the experience of teacher educators, we realised that it was important to focus on their discoveries. Collective reflection and collaborative autoethnography of four teacher educators developed into a reflective process of creating collective knowledge about their lived experience of coping with the new reality of teaching. The research was carried out in four steps: collective reflection on the context of education and individual lived experiences, collective analyses of transcribed first-person narratives, collective interpretation of the first-person narratives, co-creation of insights, and implications for the future of teacher training. The paper discusses the discoveries of four teacher educators made during the pandemic period: the benefits of communication technology, new interpersonal relations, the dynamics of self-learning, and a new concept of multiple educational spaces. The research results showed that the online teaching and technological breakthrough encouraged teacher educators to use various online platforms and technological tools, to develop new teaching strategies, to find effective ways of communication, to focus more on the organisation of teaching and learning, the usage of multiple learning spaces, and teaching multimodality. At the end of this paper, we provide some insights for teacher education: teacher education programmes should create conditions for student transformative learning preparing prospective teachers to live and work in a rapidly changing and challenging world, to create space and time to develop important qualities of student teachers such as flexibility, the ability to adapt to changing circumstances and resistance to physical and emotional disturbances.
\end{abstract}

Keywords: collaborative autoethnography, collective reflection, COVID-19 pandemic, teacher educators, the new reality. 


\section{Introduction}

Since March 2020, 1,7 billion children and youth in 188 countries were heavily affected by the unexpected closure of schools and rapid transition to distance learning (OECD, 2020). Teachers occurred in an extreme situation, which demanded them to change their traditional work routine without having the necessary IT competencies and skills. Research indicates (Eurydice, 2020) that teacher educators were facing serious challenges as well. Distance learning also forced them to spend much more time in front of screens causing harm to their health and emotional condition (Moawad, 2020). They had to solve problems of limited communication (Bao, 2020), digital exclusion (Radha et al., 2020), digital and academic ethics, all kinds of technological issues (Chen et al., 2020) as well as the loss of physical learning/teaching space and environment (Chang \& Ming, 2020; Daniel, 2020). This new reality raised questions "about the nature of teaching and ways of supporting the learning of student teachers, but it also challenges teacher education to (re) think the ways of (re)educating teachers for scenarios that are unpredictable and unknown but which raise questions related to equity and social justice" (Flores, Swennen, 2020).

Even though online learning triggered quite a few problems in the field of teacher education, simultaneously it provided new opportunities for innovation and experimentation. Teacher educators note the growth of personal and professional self-efficacy of themselves and their students. They discovered more opportunities to differentiate the study process and take into account the needs and interests of individual students, to apply a greater variety of information sources and assessment methods, to use more diverse means of communication with students, and to monitor the quality of studies more effectively (Bryson \& Lauren, 2020; Rapanta et al., 2020; Mollenkopf \& Gaskill, 2020; Wargadinata et al., 2020). In some respects, the said factors have even improved the quality of studies. Summarising research on the influence of pandemic for teacher educators, Flores and Swennen (2020) argue that on a global scale it has shocked teachers at all levels but at the same time, it inspired and motivated them "to find solutions to problems they have never encountered before the pandemic and will have to face in the near and not so near future".

Despite numerous research in the field, teaching and learning in a pandemic situation remain open to research insights. Considerations remain relevant as to what lessons for education were learned, how they will affect teacher training, what were best practices of the period, and how they can be used in the future. In this paper, we seek to discuss teacher educators' discoveries through challenges in the COVID-19 situation and, based on them, to provide insights for the future of teacher education. 


\section{Method}

The authors of the study are four researchers and teacher educators working with future teachers, doctoral students, and experienced teachers in different contexts: school, university, and non-governmental educational organization. We were scrutinising our lived experience of teaching from the start of the lockdown in March 2020 till February 2021. We combined two approaches of qualitative research: autoethnography and collective reflection. Autoethnography is a genre of the first-person narrative based on the premise that understanding the self is a way to understand others (Kim, 2016; Kathy-Ann et al., 2017). We were using collective autoethnography by pooling our lived experience on educating teachers during the lockdown and analysing and interpreting it collaboratively. The process we used was a collective reflection, which enables us to use our life stories and experience to understand and interpret the interrelationship between ourselves and others at the unique social reality of the present crisis (Roy \& Uekusa, 2020). Collective reflection helped us strengthen autoethnography by considering action and reflection as an integrated whole. There were 4 steps in the current research:

1. Collective reflection on the context of education and individual lived experiences to set the research scope. During 2 two-hour recorded Zoom sessions, we freely shared our experiences without defining specific topics and areas of experience. The session record was transcribed, the transcript consisted of 6 pages (3006 words).

2. Collective analyses of transcribed first-person narratives. We used the MAXQDA (a software package for analysing qualitative data) for thematic content analysis. The thematic content analysis consisted of three stages: pre-analysis, exploration, treatment and interpretation (Bardin, 2009). The first author of this paper had read, organized the material to the analysis (the pre-analysis stage), defined the units of analysis, and established thematic ideas for them (the exploration stage). To ensure the reliability of the coding, it was carried out by second and third researchers. After comparing the codes provided, all researchers participated in identifying the categories (the treatment and interpretation stage). We identified the underlying themes: the use of educational technologies in the study process, the characteristics of self-learning during the pandemic, transformation of interpersonal relations with students, and the combination of multiple educational spaces.

3. Collective interpretation of the first-person narratives indicating challenges and discoveries in the COVID-19 situation. When interpreting the data, we decided to focus on the discoveries of the benefits of 
educational technology, new interpersonal relations, the dynamics of self-learning, and the new concept of educational spaces.

4. Co-creation of insights and implications for the future of teacher training and professional development based on the discoveries.

We revealed four discoveries for teacher education: the benefits of communication technology, new ways for building interpersonal relations, the dynamics of self-learning, and a new concept of multiple educational spaces. We discussed them in the context of the insights and findings of other researchers. We included original excerpts from the narratives of the authors of this paper using their real names.

\section{Results}

\section{Discovering the benefits of educational technology}

The sudden transition to online teaching raised concerns among academics about their capacity to teach online by maintaining the same level of interaction with students as during face-to-face teaching (Teräs et al., 2020). Teacher educators encountered challenges arranging online classes, choosing online teaching platforms, monitoring the effect and quality of online teaching, and dealing with online tools which constrained teaching (Chen et al., 2020; Mseleku, 2020). Not active pre-pandemic use of IT prevented teachers from becoming smart users of technology, fully aware of the opportunities it provided. Rūta described her lived experience as follows:

"At the very beginning of the lockdown Zoom, Teams looked like some magic, certainly not designed for me or teaching. That's how the first two weeks passed - I ignored the situation. I was only able to prepare my lectures on PowerPoint slides and send them to students."

On the other hand, the sudden transition to online teaching led to rapid changes. What was to be learned in an uncertain future was mastered in a matter of months. This is how Rüta described her teaching experience in half a year:

"Now I'm diving in the web. I don't know what I haven't tried with my students. Sharing screens, putting them into break-out rooms, mute/ unmute, etc., that is simple. Now I can easily put out a relevant video or find something on the internet that I need promptly. It has never been like that before."

Such "diving" online and the use of various tools provided obvious satisfaction to teacher educators and significantly enriched the processes of teaching and learning. Both Rūta and the other authors of the paper discovered and enjoyed their new ability to use various online platforms and teaching tools. 
The expanded learning geography enabling the involvement of other professionals in sessions with students was another discovery of online teaching. We found an example of this in Liudmila's story:

"Ihave never had such agood chance to enrichmy courses with guestlecturers! Thus, e. g., I was giving a course on the phenomenological approach. I invited two of my former doctoral students who applied it in their dissertations... An even more striking example was a collaboration with distinguished professor David Bloome from Ohio State University (USA). David took part in our online lectures for one hour twice a month. We would never have had such a luxury in the old routine of teaching/ learning."

Online education enabled us to enrich our teaching by inviting other people to take part in our classes, especially those who had unique competencies or practical experience useful for students.

We discovered other benefits of online education, such as flexibility, when teachers and students have the freedom to join the session from different spaces and geographically remote locations; reduced costs of travel and premises; saved time; unlimited access to information sources, and easier sharing of information. Although we were aware of those benefits, in theory, it was only during the pandemic that we discovered them as a personal opportunity to improve the quality of teaching and learning.

\section{Discovering new interpersonal relations}

Direct contact with another person in the process of learning is one of the most important conditions for effective teaching and learning (Gablinske, 2014; Japutra \& Wang, Li, 2021). For a long time, it has been a routine practice for us; it helped to build interrelationships and develop social skills. During the pandemic, a huge change took place because we realised that we can no longer continue to work and communicate as before. Limited, in some cases, only one-way communication during lectures caused serious concerns (Arefi, 2021). It complicated fostering and building interpersonal relationships, the development of a favourable emotional microclimate, and collaboration. Remigijus's and Liudmila's narratives illustrate how it was confusing to establish and maintain the relationship with students at the beginning of the online teaching era:

"Quite often, I was talking to black windows. In such cases, I was addressing students personally. Afterward, I could hear a sound from that dark window and I was doing my best trying to get them involved in our discussion." (Remigijus)

"It looked like you could no longer understand what was going on behind the screen. Earlier you could sense body movement or a glance but now you felt completely isolated from non-verbal information... It was obvious 
that I needed to change something and look for new ways of communication." (Liudmila)

Since there was no clear understanding of how learners acted in the digital space, since we did not know or understand students' expectations and needs, we had to remodel and revise the tasks and the very design of classes. Re-evaluation of the personal contribution in creating two-way communication became particularly important. One of the main discoveries for us was the new understanding of the social perception process, the interpretation of non-verbal language signals. Rūta's narrative illustrated that experience:

"Now, I see very well them privately corresponding with each other in those chats, and I can tell who is corresponding with whom because the one who was writing smiled and another who was answering smiled back... and I don't want to forbid this to them because it is still a way of communication..."

Re-evaluation and change of attitudes, approaches, and beliefs became one of the main factors predetermining the successful development of interpersonal relationships in the digital space. We realized that in distance contacts, it was important to change both our own and student ways of communication and the maintenance of relationships. It was important for us to put up with the current situation and not to be afraid to change, learn, and acquire the necessary skills. That helped us to establish contact with students. The wish to be efficient and important enabled one to learn by analysing both one's own and learners' emotional and teaching/learning experiences.

\section{Discovering dynamics of self-learning}

Since the beginning of the lockdown, our perception of teaching in a "disembodied" virtual space has changed dramatically. We experienced the dynamics of being pushed past our "comfort zone" to the "panic zone" and it took some time for us to move to a "learning zone" (Colvin, 2008). We were forced to become "expert learners" through "deliberate practice which involved risk-taking" (Stobart, 2014, p. 50). Such a turn from experiencing a challenge to discovering new possibilities is demonstrated by Liudmila's narrative:

"I believed that online learning could be effective only when there was no other way to meet live, that live interaction was extremely important... And suddenly it came to a halt. But a year later I understood that I would never come back. I realised that virtual meetings and digital learning offered a lot of new opportunities and have huge potential."

The "new reality" shook us quite radically. To acquire new IT skills and develop new routines was an easy part. Much more difficult was to 
confront our own identities as teacher educators, questioning the meaning of our professional lives and raising questions about our capacity to support teachers in real crises. We had little experience or knowledge of how to do it, and not much time to learn. Eglè shares her experience:

"After schools were closed and teachers dived into online learning, my work as a teacher educator stopped for some time. I felt lost, helpless, and useless. I got into a "panic zone": what could I offer teachers at this point? Their needs were completely different from what I could offer; online learning was not my expertise. It took some time to understand the new reality and find out how I could be useful again..."

The experience represented the transformational process of self-awareness of a teacher educator in a new, unfamiliar, and unpredictable context. The new reality pushed her past the "comfort zone" toward the need to adapt to a new educational context in a very short time. That stage can be understood as providing opportunities for growth because when we "move outside the comfort zone into the learning zone we are being stretched to master new skills and knowledge" (Stobart, 2014, p. 51). Rūta comments on the changes that have taken place:

"I used to think that "distance learning" was something very sophisticated. Previously at the university, we had to use a special room for that and only an IT assistant could arrange it. Since the spring, learning IT tools was extremely fast. I could not imagine that I could do it from my home. Now I'm managing zoom conferences for 500 participants, I'm juggling easily with 5-6 opened video files during my sessions. Feeling competent with IT makes a big difference and it allows you to see its opportunities."

To sum up the dynamics of our learning during a year of lockdown, we can call it a transformative learning experience. According to Meijer, such experiences or shifts shatter our identity and break the orientation but later it helps us to change "in order to get any further" (Meijer, 2011, p. 14). This experience is transforming us as teacher educators and gives us ideas on how we should create a transformative learning environment for our students.

\section{Discovering a new concept of multiple educational spaces}

The idea of multiple educational spaces is not new. Distance education, e-learning, online learning is a well-known form of education in which the main elements include physical separation of teachers and students during instruction and the use of various technologies (Radugin et al., 2020). In the COVID-19 situation, not only is online instruction used, but the concept of space itself is changing. Rüta offers her story how a current lecture takes place: 
"When I look at the screen during the lecture, I see my 25 students. Each of them is in their own space, and at the same time, we are together on one screen. They experience the same thing. We are all in one another's homes. Probably while listening to me and looking at the screen, they are checking social networks and news portals. When asked, they find information in a virtual library or websites. I also check the course data myself in the Google classroom system, sometimes my e-mail as well. And it's all on one screen."

The teacher sees all of her 25 students on one screen who are in their private space. The 26 teacher and student spaces fit in one screen: they all are in one another's homes. Moreover, the students admitted that during lectures they are not only performing the tasks provided by the lecturer but checking their e-mail, Facebook news, visiting virtual libraries, and online portals. The learning space is both reduced to a single screen and simultaneously expanded virtually and geographically. The new routine means giving lectures to students scattered all over Lithuania or learning from different countries or even different continents.

The learning space becomes disembodied. These are no longer buildings, rooms, or halls but websites. As Pacheco argues, when "moving from physical face-to-face presence to virtual contact (synchronous and asynchronous), the learning space becomes disembodied, virtual, not actual, impacting both student learning and the organization of schools, which are no longer buildings but websites" (Pacheco, 2020, p. 3). We act, work, and communicate no longer in the first or second, but in the third space. In this space, new cultural identities are formed, reformed, and constantly in a state of becoming. Moreover, that presence in the third space changes us. We work across internal and external boundaries of educational spaces and create "new institutional spaces, knowledge and relationships" (Whitchurch, 2008, p. 386). We lose our presence here and now. As Remigijus says, "we are teaching and learning in virtual space, it seems to students that they can afford to be in two or three places. ... they can combine multiple tasks, being in several places". Networking, laterality, hybridity, flexibility, multi-tasking becomes important features of the newly created educational spaces (Taylor, 2008).

\section{Discussion}

Despite the numerous publications in recent years on the impact of the pandemic on education, the issues of learning and teaching during the lockdown, and the related challenges and opportunities, quite a few questions remain unanswered. With a view to the future, researchers seek to find out how the lockdown affected the higher education sector (Mseleku, 2020), 
the impact of the online transfer on student learning habits (Wargadinata et al., 2020), and academic outcomes (Mseleku, 2020), the advantages and disadvantages when comparing offline and online learning (Radha et al., 2020), and the lockdown experiences and lessons relevant to the field of teacher education (Mollenkopf et al., 2020; Wargadinata et al., 2020, Flores, Swennen, 2020). In our study, we focused on the challenges faced by teacher educators due to a sudden transition from offline to online teaching and evaluated the experiences of coping with them as discoveries significant for the future practice of teacher education. Our discoveries are believed to be not merely the solutions of the encountered problems but also effective ways of teaching teachers "how to teach, facilitate and encourage learning, both explicitly, via lectures, seminars, and tutorials, and implicitly, by modelling (...) what it means to be a professional teacher" (European Commission 2013, p. 8).

The sudden transition from face-to-face to online learning brought numerous challenges for teacher educators (Mollenkopf et al., 2020). If the difficulties in online teaching analysed in the above-mentioned studies were mostly dealt with as individual cases, the COVID-19 situation revealed their complexity and relevance to higher education in general (Mseleku, 2020). As demonstrated in our paper, at the beginning of the lockdown, teacher educators lacked the knowledge and habits of use ICT in the process of studies, they experienced difficulties in the interaction between teachers and students. They had to rethink the concept of educational space as well as to deal with the problems of emotional and physical well-being. Every challenge we faced during the year of the lockdown brought us important discoveries. We learned how to use various online platforms and technological tools to improve the quality of studies. We discovered new strategies for communicating with students and used virtual educational spaces and multimodal learning. There is still a shortage of research on the benefits of new modes of learning during the COVID-9 pandemic.

The paper is based on the approach of social constructionism which centres on the notion that meanings are constructed by individuals in relation with others to understand the existing reality (Berger \& Luckmann, 1966; Burr, 2003). New reality pushed us from the "comfort zone" forced us to acquire new skills, and changed our beliefs and stereotypes about distance learning. This transformative learning experience helped us reconsider important questions of our professional identity and the future of our work, this dynamic experience is reflected in our stories. The COVID-19 situation encouraged us to include innovation in the teacher training process and provided us with new opportunities for our professional development. 


\section{Conclusions and insights for teacher education}

On summarizing our experience and research findings, we can argue that the chosen methodological approach through reflection and sharing experience enabled us as researchers to reveal the meaning of the current situation and to identify opportunities. Through reflecting on our experience, we discovered that the online teaching and technological breakthrough during the lockdown brought a lot of advantages into our academic practice. In a very short time, we learned not only how to use various online platforms and technological tools, but how to apply them flexibly when working with students. The absence of direct communication encouraged us to develop social awareness and communication skills through testing new online teaching strategies. Changes in relationships made it possible to rethink attitudes and beliefs by finding more effective ways to build and maintain relationships to compensate for the limitations of distance communication. The changed concept of the learning and teaching space freed us from caring about physical spaces and obliged us to focus more on the organisation of teaching and learning, the usage of multiple learning spaces (virtual libraries, video resources), and teaching multimodality.

It has become clear that we must think about a new routine for the new future, taking into consideration the multifaceted challenges of the "new normality". As Žižek $(2020$, p. 3) argues that "there is no return to normal, the new 'normal' will have to be constructed on the ruins of our old lives, or we will find ourselves in a new barbarism whose signs are already clearly discernible". Prospective teachers need to be prepared to live and work in a rapidly changing and challenging world. Flexibility, the ability to adapt to changing circumstances, and resistance to physical and emotional disturbances are the qualities of teachers made particularly relevant by the COVID-19 situation. Therefore, teacher education programmes should create conditions for student transformative learning where they could take risks and face challenges to be better prepared for the uncertainties of the "new normal". For transformative learning, teacher educators should create communities of trust, build space and time for reflection, and encourage students to confront their painful and stressful experiences as well as identity issues.

\section{References}

Arefi, M. (2021). COVID-19 and Remote Teaching. Academia Letters, Article 476. Retrieved from: https://www.academia.edu/45584281/COVID_19_and_Remote_Teaching

Bardin, L. (2009). Content analysis. Lisbon: Editions, 70.

Bao, W. (2020). COVID-19 and online teaching in higher education: A case study of Peking University. Human Behaviour and Emerging Technologies, 2(2), 113-115. 
Berger, P. L., \& Luckmann, T. (1966). The Social Construction of Reality: A Treatise in the Sociology of Knowledge. New York: Doubleday \& Company.

Bryson, J. R., \& Lauren, A. (2020). COVID-19 and rapid adoption and improvisation of online teaching: curating resources for extensive versus intensive online learning experiences. Journal of Geography in Higher Education, 1-16.

Burr, V. (2003). Social Constructionism ( $2^{\text {nd }}$ ed.). London: Routledge.

Chang, Ch., \& Ming, F. (2020). E-Learning and Online Instructions of Higher Education during the 2019 Novel Coronavirus Diseases (COVID-19) Epidemic. Journal of Physics: Conference Series, 1574(1), 012166.

Chen, T., Lijuan, P., Xiaohua, Y., Jingtao, R., Jianjun, Y., \& Guodong Cong (2020). Analysis of user satisfaction with online education platforms in China during the COVID-19 pandemic. Healthcare, 8(3), 200.

Colvin, G. (2008). Talent is Overrated: What Reality Separates World-Class Performers from Everybody Else. London: Nicolas Brealey.

Daniel, S. J. (2020). Education and the COVID-19 pandemic. Prospects, 49, 91-96.

Eurydice. (2020). How is COVID-19 affecting schools in Europe? Retrieved from: https:// eacea.ec.europa.eu/nationalpolicies/eurydice/content/how-COVID-19-affectingschools-europe_en.

Flores, M. A. Swennen, A. (2020) The COVID-19 pandemic and its effects on teacher education, European Journal of Teacher Education, 43(4), 453-456, DOI:10.1080/026 19768.2020.1824253.

Gablinske, P. B. (2014). A case study of student and teacher relationships and the effect on student learning. Open Access Dissertations. Paper 266. Retrieved from: https:// digitalcommons.uri.edu/oa_diss/266

Japutra, A., Wang, S., \& Li, T. (2021), The influence of self-congruence and relationship quality on student educational involvement. Journal of Marketing for Higher Education, DOI: $10.1080 / 08841241.2021 .1884928$

Kathy-Ann, C., Hernandez, H. Ch., \& Ngunjiri, F. W. (2017). Collaborative Autoethnography as Multivocal, Relational, and Democratic Research: Opportunities, Challenges, and Aspirations. Auto/Biography Studies, 32(2), 251-254, DOI: 10.1080/08989575.2017. 1288892

Kim, J-H. (2016). Understanding Narrative Inquiry. SAGE Publications, Inc.

Meijer, P. C. (2011). The Role of Crisis in the Development of Student Teachers' Professional Identity. In: A. Lauriala, R. Rajala, H. Ruokamo \& O. Ylitapio-Mäntylä (Eds.), Navigating in Educational Contexts (pp. 41-54). Rotterdam: SensePublishers.

Moawad, R. A. (2020). Online Learning during the COVID-19 Pandemic and Academic Stress in University Students. Revista Românească pentru Educaţie Multidimensională, 12(1), 100-107.

Mollenkopf, D., \& Gaskill, M. (2020). Creating Meaningful Learning Experiences for Pre-Service and In-Service Teachers Facing Interruptions in Field Experience Placements During the COVID-19 Pandemic. In: R. E. Ferdig, E. Baumgartner, R. Hartshorne, R. Kaplan-Rakowski, \& C. Mouza (Eds.), Teaching, Technology, and Teacher Education During the COVID-19 Pandemic: Stories from the Field (pp. 347-354). AACE-Association for the Advancement of Computing in Education.

Mseleku, Z. (2020). A Literature Review of E-Learning and E-Teaching in the Era of COVID-19 Pandemic. International Journal of Innovative Science and Research Technology, 5(10), 588-597. 
OECD (2020). Education and COVID-19: Focusing on the long-term impact of school closures.

Pacheco, J. A. (2020). The "new normal" in education. Prospects. https://doi.org/10.1007/ s11125-020-09521-x

Radha, R., Mahalakshmi, K., Sathis Kumar, V., \& Saravanakumar, A. R. (2020). E-learning during lockdown of COVID-19 pandemic: a global perspective. International Journal of Control and Automation, 13(4), 1088-1099.

Radugin, A., Radugina, O., \& Nazarenko, K. (2020). Virtualization of the educational space and educational process in the information society. Proceedings of SOCIOINT, 2020( $\left.7^{\text {th }}\right)$, 190-195.

Rapanta, Ch., Botturi, L., Goodyear, P., Guàrdia, L., \& Koole, M. (2020). Online university teaching during and after the COVID-19 crisis: Refocusing teacher presence and learning activity. Postdigital Science and Education, 1-23.

Roy, R., \& Uekusa, S. (2020). Collaborative Autoethnography: "Self-Reflection" as a Timely Alternative Research Approach during the Global Pandemic. Qualitative Research Journal, 20(4), 383-392.

Stobart, G. (2014). The Expert Learner. NY: Open University Press.

European Commission. (2013). Supporting teacher educators for better student outcomes. https://ec.europa.eu/assets/eac/education/policy/school/doc/support-teachereducators_en.pdf

Taylor, P. (2008). Being an academic today. In: R. Barnett \& R. Di Napoli (eds.), Changing identities in higher education: Voicing perspectives (pp. 27-39). Abingdon: Routledge.

Teräs, M., Suoranta, J., Teräs, H., \& Curcher, M. (2020). Post-COVID-19 education and education technology 'solutionism': A seller's market. Postdigital Science and Education, 2, 863-878.

Wargadinata, W., Maimunah, I., Eva, D., \& Rofiq, Z. (2020). Student's responses on learning in the early COVID-19 pandemic. Tadris: Journal of Education and Teacher Training, 5(1), 141-153.

Whitchurch, C. (2008). Shifting identities and blurring boundaries: The emergence of third space professionals in UK higher education. Higher education quarterly, 62(4), 377-396.

Žižek, S. (2020). PANDEMIC! COVID-19 Shakes the World. New York and London: Or Books. 